\title{
Balance Assessment in Children with Down Syndrome Who Practice Dance
}

\author{
${ }^{1}$ Carla Cristina Vieira Lourenço ${ }^{(D *}{ }^{*}{ }^{2}$ Geiziane Leite Rodrigue Melo ${ }^{i D},{ }^{3}$ Elvio Marcos \\ Boato \\ ${ }^{1}$ Department of Sport of Science, University of Beira Interior, Covilhã, Portugal. ${ }^{2}$ Centre for Studies in \\ Education and Innovation (CI\&DEI), Viseu, Portugal. ${ }^{3}$ State Department of Education of the Federal \\ District, Brasilia, Brasil.
}

Submitted 15 February 2021; Accepted in final form 10 May 2021.

\begin{abstract}
Background. It is observed that dance delivers a valuable contribution to the development of bodily motor functions. Objectives. To evaluate the static and dynamic balance in children with Down syndrome - DS enrolled in a Dance Workshop for people with disabilities. Methods. Balance tests proposed by Oliveira (2009) were used on 14 children with DS aged between 8 and 12 (mean $9.36 \pm 1.2$ years.). Who has been practicing dance for not less than two years? A Control Group was formed with 14 children with DS who do not dance with the same age group (mean $9.43 \pm 1.09$ years). Results. While the maximum effect of the proposed tests is 12 points and $42.08 \%$ of the sample obtained a score below 5. It is considered relevant the percentage of $57.13 \%$ of the participants to have scored five, six, or seven. It can be stated that dance proved too significant a considerable means of stimulating balance development in children with DS. It was considering the results regarding the CG that pointed to $42.25 \%$ of the sample with a score of zero and $57.25 \%$ with a rating of 4,3 , or 2 . Conclusion. The constant and systematic dance practice can present a considerable development in the balance of children with DS. This favors their inclusion and permanence in physical exercise and sports programs.
\end{abstract}

\section{KEYWORDS: Balance, Dance, Down Syndrome.}

\section{INTRODUCTION}

Down Syndrome (DS) is characterized by a chromosomal anomaly on chromosome 21 and its comorbidities like congenital heart disease in more than $50 \%$ of cases, changes in the spine, thyroid disorders, obesity (1-7), premature aging (8), cerebellar hypoplasia and problems with brain stem development (9), in addition to visual, auditory and central auditory processing deficits, lead to slow growth in general skills, considering motor skills and cognition.

Individuals with DS experience a delay in acquiring motor skills compared to other children without DS. This obstruction can impair tasks that require manual dexterity and grip strength (10). Otherwise, they present difficulties in terms of the acceptable motor profile (11).

The literature also reports the existence of motor alterations in children with DS, such as those related to the development of gait, static and dynamic balance, and space-time gait parameters that are substantially different between kids with and without DS (2). Considering that the equilibrium and walking ability of ordinary developing kids improve during growth, while children with DS remain shallow despite independent walking. However, the development

*. Corresponding Author:

Carla Cristina Vieira Lourenço

E-mail: ccvl@ubi.pt 
cycle follows similar characteristics of people without DS (1-7).

Balance is one of the critical factors that affect the safety and independence skills of children with DS (2). This is fundamental for independent gait and motor coordination, and problems affect the construction of the body scheme (6). Such issues, referring to balance, may be related to muscle hypotonia, ligament laxity, flat foot, cerebellar hypoplasia $(1,9,12,13)$, in addition to the small brainstem (9) and impaired vision and hearing, which are striking features in children with DS.

Problems in balance can cause difficulties in the execution of motor skills, which is why interventions with children with DS must consider the development of diverse motor skills and balance (14) because it is fundamental for the practice of physical exercise, represent a skill that maintains the center of gravity within the support base with a limited amount of oscillation, therefore, it is essential for postural control and physical activity in general (2).

Therefore, the need for physical exercise, training the complete motor experience is considered so that there is a balance improvement in the development of children with DS (9), having been verified that in interventions with physical exercises, the children with DS show better results in balance tests than the control groups (15). In this manner, to stimulate the development of balance in children with DS, one of the activities that can be used is a type of dance that provides conditions for their psychomotor, cognitive, and emotional development (16).

The dance represents a highly significant power due to the symbolic language in terms of movement, space, and time. Thus, all the faculties of the human being, both cognitive and physical and affective, characterized by the rhythmic and harmonious use of all bodily, mental, and spiritual functions, are put into play, because when dancing, the muscles, the senses, the mind enter in an activity, combining each other, communicating thoughts and emotions (17).

Additionally, dance practice improves motor functions like coordination, balance, flexibility, resistance, agility, and elasticity (18) and the development of conditions for the preparation of other physical exercises for promoting sensory integration and postural control (19, 20). Therefore, and considering the results obtained in this study, dance becomes an ideal tool for stimulating the development of balance in people with DS since its maintenance is essential for the performance of any human activity and physical well-being and emotional $(21,22)$. On this account, it is observed that dance delivers a valuable contribution to the development of bodily motor functions. As a result, the objective of the present study was to evaluate the static and dynamic balance in children with DS enrolled in a Dance Workshop for people with disabilities.

\section{MATERIALS AND METHODS}

Participants. Fourteen participants with DS aged between 8 and 12 years (average of $9.36 \pm$ 1.2 years) enrolled in the Dance Workshop of the Extension and Research Project in Specialized Educational Care in Physical Education, and Art (dance) for People with Disabilities was selected.

The dance project in question proposes psychomotor stimulation based on the Psychomotor Education method of Le Boulch $(1992,1987,1983)$ and aims, in addition to the student's integral development, the formation of choreographies that are presented to family and community in general.

The Research Group (GP) was selected for convenience, being formed by $100 \%$ of children with Down syndrome enrolled in the dance project, being composed of 6 female and eight male children, and the inclusion criteria were: having the ability to understand and perform the proposed tests, having written permission from the parents to participate in the study and study and not participate in another physical exercise program. The exclusion criterion was suffering a cardiac problem with the indication for surgery not yet performed or atlantoaxial instability confirmed by an X-ray report of the spine. No child enrolled in the dance project met any of the exclusion criteria.

All participants did at least two years of practice in the workshop, participating in two weekly classes lasting 40 minutes each.

A Control Group (CG) was also arranged with 14 participants of the same age group and DS (average of $9.43 \pm 1.09$ years), composed of 6 women and eight men who did not participate in any regular dance program. However, they all received Specialized Educational Assistance in Physical Education at schools in the Public Schools of the Federal District (Brazil), where they were enrolled. 
All study participants (RG and GC) were enrolled in Elementary School in regular classes, together with students who do not experience disabilities, being distributed in the 1st, 2nd, and 3rd years.

Table 1. Balance Tests (Oliveira, 2009)

\begin{tabular}{|c|c|}
\hline Test & Proceedings \\
\hline \multicolumn{2}{|c|}{$\begin{array}{l}\text { Static balance } \\
\text { (OZERETSKI, -GUILMAN) }\end{array}$} \\
\hline T1 immobility & $\begin{array}{l}\text { The child should stand up with } \\
\text { his eyes closed, arms lying } \\
\text { sideways, and legs slightly } \\
\text { open for one minute. }\end{array}$ \\
\hline $\begin{array}{l}\text { T2 e T3 One foot with } \\
\text { eyes closed }\end{array}$ & $\begin{array}{l}\text { The child must remain on only } \\
\text { one leg while the other } \\
\text { remains at a right angle to the } \\
\text { knee. The hands should be } \\
\text { loose along the body and the } \\
\text { eyes closed. The feet must be } \\
\text { alternated; the test must be } \\
\text { applied with the left and the } \\
\text { right leg. }\end{array}$ \\
\hline
\end{tabular}

Observed Aspects

Score

Mobility or swing of the body; if the child has tension, stiffness or correct posture; if there is the abduction of the arms (they rise to maintain balance); presence of synkinesis; if you remain with your eyes closed; the difference in quality from one side to the other.

Mobility or swing of the body; if the child has tension, stiffness or correct posture; if there is the abduction of the arms (they rise to maintain balance); presence of

synkinesis; if you remain with your eyes closed; the

difference in quality from one side to the other.

2 Points: Perfect, economical, harmonic, precise performance, correct posture;

1 Point: Performance with some control difficulties, slight swings, with little tension and small rigidity, light synkinesis;

0 Point: Failure to perform movements, imbalance, lack of coordination, stiffness, great muscle tension.

2 Points: Perfect, economical, harmonic, precise

performance, correct posture;

1 Point: Performance with some control difficulties, slight swings, with little tension and small rigidity, light synkinesis;

0 Point: Failure to perform

movements, imbalance, lack of coordination, stiffness, excellent muscle tension.

\section{Dynamic balance}

T4 e T5 Stand on leg and jump with one foot with eyes open
Jump for a distance of approximately $5 \mathrm{~m}$ on one leg, while the other remains bent at right angles. Hands should be at your sides. The time taken by the child to reach the goal is not considered. The feet must be alternated; that is, the test must be applied with the left and the right leg.
The search of the body axis; observe the choice of the right or left side and the difference in execution between the two sides; posture; speed or slowness when performing tasks; global coordination; and the same observations of static balance.

\section{Points: Perfect, economical,} harmonious, precise performance, correct posture; clap three in exercise 2; 1

Point: Performance with some control difficulties, with little tension and little rigidity, synkinesis; clapping hands 2 in exercise 2;0 Point: Failure to perform movements, imbalance, lack of coordination, stiffness,

excellent muscle tension. Beat your hands one or not at all in exercise 2.

2 Points: Perfect, economical, harmonious, precise

performance, correct posture; clap three in exercise $2 ; 1$

Point: Performance with some control difficulties, with little tension and little rigidity, synkinesis; clapping hands 2 in exercise 2;0 Point: Failure to perform movements, imbalance, lack of coordination, stiffness, excellent muscle tension. Beat your hands one or not at all in exercise 2.

Total score
To obtain the total score in the tests, initially, the static balance scores were added and then the dynamic balance scores were added. Finally, the dynamic balance scores were added to the static
Data Collection Procedures. The application of the tests in the RG happened during the classes of the Dance Workshop and was submitted by the teacher responsible for the same. They considered 
the affective bond with students and the fact that she knew the psychomotor tests presented and expertise for its application. The researcher followed the demand of all tests, attesting to their reliability.

In the CG, the researcher carried out the tests in the school where each child attended, in a room designed for this purpose, with the student, their teacher, and the researcher.

To carry out this study, the Static and Dynamic Balance Tests proposed by Oliveira (2009) (Table 1) were utilized, seeking to trace a profile of the development of the balance of students with DS, using measures percentage to indicate the level of progress of the group in question. These tests were published in a book by Editora Vozes in 2009 with the title "Psychomotor Assessment in the light of Psychology and Psychopedagogy" and are currently in the 13th edition (23).

Opinion of the Research Ethics Committee. The Research Ethics Committee approved the research work with protocol number 67645217.7.0000.0029 and Consubstantiated Opinion number 2.147.985.

\section{RESULTS}

Table 2 shows the results obtained in the six balance tests ( 3 for static balance and 3 for dynamic balance) applied in the Research Group (RG) and the Control Group (CG).

Table 2. Results of Static and Dynamic Balance Tests (Oliveira, 2019)

\begin{tabular}{|c|c|c|c|c|c|}
\hline \multirow{2}{*}{$\begin{array}{l}\text { Research Group } \\
\text { Maximum Score (2) }\end{array}$} & \multicolumn{5}{|c|}{ Control Group } \\
\hline & $\begin{array}{l}\text { Average } \\
\text { Score (1) }\end{array}$ & $\begin{array}{l}\text { Minimum } \\
\text { Score }(0)\end{array}$ & $\begin{array}{c}\text { Maximum } \\
\text { Score }(2)\end{array}$ & $\begin{array}{l}\text { Average } \\
\text { Score (1) }\end{array}$ & $\begin{array}{c}\text { Minimum } \\
\text { Score }(0)\end{array}$ \\
\hline \multicolumn{6}{|c|}{ T1 - immobility (Static Balance } \\
\hline 8 & 5 & 1 & 3 & 5 & 6 \\
\hline $57.1 \%$ & $35.8 \%$ & $7.1 \%$ & $21.4 \%$ & $35.8 \%$ & $42.9 \%$ \\
\hline \multicolumn{6}{|c|}{$\begin{array}{l}\text { T2 - Right foot with eyes closed (Static } \\
\text { Balance) }\end{array}$} \\
\hline 1 & 6 & 7 & 0 & 5 & 9 \\
\hline $7.1 \%$ & $42.9 \%$ & $50 \%$ & $0 \%$ & $35.7 \%$ & $64.3 \%$ \\
\hline \multicolumn{6}{|c|}{$\begin{array}{l}\text { T3 - Left foot with eyes closed (Static } \\
\text { Balance) }\end{array}$} \\
\hline 2 & 6 & 6 & 0 & 0 & 14 \\
\hline $14.2 \%$ & $42.9 \%$ & $42.9 \%$ & $0 \%$ & $0 \%$ & $100 \%$ \\
\hline \multicolumn{6}{|c|}{$\begin{array}{l}\text { T4 - Jump right foot with eyes open } \\
\text { (Dynamic Balance) }\end{array}$} \\
\hline 5 & 4 & 5 & 0 & 7 & 7 \\
\hline $35.7 \%$ & $28.6 \%$ & $35.7 \%$ & $0 \%$ & $50 \%$ & $50 \%$ \\
\hline \multicolumn{6}{|c|}{$\begin{array}{l}\text { T5 - Jump left foot with eyes open } \\
\text { (Dynamic Balance) }\end{array}$} \\
\hline 4 & 7 & 3 & 0 & 0 & 14 \\
\hline $28.6 \%$ & $50 \%$ & $21.4 \%$ & $0 \%$ & $0 \%$ & $100 \%$ \\
\hline \multicolumn{6}{|c|}{$\begin{array}{l}\text { T6 - Jumping clapping (Dynamic } \\
\text { Balance) }\end{array}$} \\
\hline 3 & 7 & 4 & 0 & 0 & 0 \\
\hline $21.4 \%$ & $50 \%$ & $28.6 \%$ & $0 \%$ & $0 \%$ & $0 \%$ \\
\hline
\end{tabular}

The results obtained in the static and dynamic balance tests in children with DS (Table 2) showed scores below the level of the standards of competence proposed in the assessments in subjects without DS.

However, in the specific case of RG, as shown in Table 2, concerning the static equilibrium in which the child remained with both feet on the ground (T1), $57 \%$ of the study participants established an appropriate balance, with a rating of 2 and $35.8 \%$ obtained an average result and only one subject $(7.1 \%)$ had a minimum score. In the $\mathrm{CG}$, it was observed that only $21.4 \%$ of the sample achieved an outcome of 2,35.7\% scored 1 , and $42.9 \%$ scored 0 in the same test. Results that point to the most satisfactory performance of the group that practiced dance.

In the other two static balance tests (T2 and T3), whose difficulty is more pronounced than $\mathrm{T} 1$, we can encounter a more substantial delay in the development of the participants. In T2, only one child $(7.1 \%)$ had a maximum score. Half $(50 \%)$ of the children gained a minimum score and $42.9 \%$ obtained an average score, close to the T3 results of static balance. Only 2 contributors $(14.2 \%)$ obtained a maximum score 
and $42.9 \%$ minimum grade. In the $\mathrm{CG}$, no member attained 2, 35.7\% scored 1 and $64.2 \%$ scored 0 in T2, whereas in T3, $100 \%$ of participants got 0 .

Tables 3, 4, and 5, presented below, represent the individual results of the research participants in the $\mathrm{RG}$ and $\mathrm{GC}$.

Tables 3, 4, and 5 show that none of the children who participated in the research $(\mathrm{RG}$ and $\mathrm{CG})$ managed to reach the maximum score in the balance tests that would be 12 . However, despite all the considerations in this study regarding the development of children with DS and the problems found in their balance. The result showed that $57.14 \%$ of RG participants with ratings 5, 6, and 7 could be considered satisfactory, whereas, in the CG (Tables 4 and 5), only three participants scored $4(21.42 \%$ of the sample). Two contributors scored $3(14.28 \%)$ and three scores $2(21.42 \%)$, with 6 participants got $0(42.75 \%)$.

Table 3. The Score of Static and Dynamic Balance tTests. Research Group

\begin{tabular}{lccc}
\hline Participants & Static Balance & Dynamic Balance & Total \\
\hline $\mathbf{0 1}$ & 3 & 4 & 7 \\
$\mathbf{0 2}$ & 4 & 3 & 7 \\
$\mathbf{0 3}$ & 3 & 3 & 6 \\
$\mathbf{0 4}$ & 3 & 3 & 6 \\
$\mathbf{0 5}$ & 3 & 2 & 5 \\
$\mathbf{0 6}$ & 2 & 3 & 5 \\
$\mathbf{0 7}$ & 2 & 3 & 5 \\
$\mathbf{0 8}$ & 2 & 2 & 5 \\
$\mathbf{0 9}$ & 3 & 2 & 4 \\
$\mathbf{1 0}$ & 2 & 0 & 4 \\
$\mathbf{1 1}$ & 4 & 3 & 4 \\
$\mathbf{1 3}$ & 1 & 1 & 3 \\
$\mathbf{1 4}$ & 2 & 1 & 2 \\
\hline
\end{tabular}

Table 4. The Score of Static and Dynamic Balance Tests. Control Group

\begin{tabular}{lccc}
\hline Participants & Static Balance & Dynamic Balance & Total \\
\hline $\mathbf{0 1}$ & 03 & 01 & 04 \\
$\mathbf{0 2}$ & 03 & 01 & 04 \\
$\mathbf{0 3}$ & 03 & 01 & 04 \\
$\mathbf{0 4}$ & 02 & 01 & 03 \\
$\mathbf{0 5}$ & 02 & 01 & 03 \\
$\mathbf{0 6}$ & 01 & 01 & 02 \\
$\mathbf{0 7}$ & 01 & 01 & 02 \\
$\mathbf{0 8}$ & 01 & 01 & 02 \\
$\mathbf{0 9}$ & 01 & 00 & 00 \\
$\mathbf{1 0}$ & 00 & 00 & 00 \\
$\mathbf{1 1}$ & 00 & 00 & 00 \\
$\mathbf{1 2}$ & 00 & 00 & 00 \\
$\mathbf{1 3}$ & 00 & 00 & 00 \\
\hline $\mathbf{1 4}$ & 00 & 00 & 00 \\
\hline
\end{tabular}

Table 5. Final Results Research Group and Control Group

\begin{tabular}{lcccc}
\hline Score & Research Group, Total & Control Group \% & Total & \% \\
\hline $\mathbf{7}$ & 2 & 14,28 & 0 & 0 \\
$\mathbf{6}$ & 2 & 14,28 & 0 & 0 \\
$\mathbf{5}$ & 4 & 28,57 & 0 & 0 \\
$\mathbf{4}$ & 3 & 21,42 & 3 & 21,42 \\
$\mathbf{3}$ & 1 & 7,14 & 2 & 14,28 \\
$\mathbf{2}$ & 1 & 7,14 & 3 & 21,42 \\
$\mathbf{0}$ & 1 & 7,14 & 6 & 42,75 \\
Total & 14 & 100 & 14 & 100 \\
\hline
\end{tabular}




\section{DISCUSSION}

Although $42.08 \%$ of the sample received a score below five, and one participant had a 0 out of a possible 12 points. It can be noted that, in this study, dance proved to represent an effective means of stimulating the development of balance in children with DS. The findings of this study are also supported by research on Alsakhawi \& ElShafey (9) and Maiano et al. (15). For whom motor stimulation and exercise (in the case of this work performed with the use of dance based on the principles of Psychomotor Education) are effective in developing static and dynamic balance in children with DS.

The factor that allows a proper understanding of the results is that the standards are established for children out of the syndrome spectrum. Put differently, children with DS have results below average because they have the following comorbidities: ligament looseness, hypotonia (13), cerebellar hypoplasia $(13,24)$, and flat foot, which is characterized by the collapse of the plantar arch and which can cause changes in the distribution of plantar pressures and modification of the axes of the subtalar. Mid-Tarsi and tarsusmetatarsal joints (25) can also lead to muscle imbalances, mainly in the posterior tibial, fibular, and long lateral muscles (26) and articular muscles in the entire lower limb. In addition, there are many cases of visual and auditory problems, with failures in the neuro-sensory processing that cause changes in the balance of children with DS (27). However, considering all these problems, the RG presented results much more significant than the CG, which may, once again, point to proper performance in the tests of static balance in children with DS who practice dance.

Considering all these problems, the GP presented results much more significant than the CG, which may indicate a more satisfactory performance in the balance tests of children with DS who practice dance. It is necessary to consider the balance is multifactorial, depending on several mechanisms to materialize (19). Therefore, it is not possible, within the conditions of this study, to determine a particular cause for the data found. It is also emphasized that, although all children of the GP have been dancing for at least two years and are in the same age group, there was considerable variability in the results between them. While the highest score (6) was achieved nothing but two children, one of them got a score of 0 and another with a score of 2. Such differences were also observed by Gutiérrez-Vilahú et al. (19) in their study. The authors suggest the inclusion of more specific exclusion criteria.

Nonetheless, considering the difficulty of forming homogeneous groups with DS, the inclusion criteria used in this research were favorable. It is necessary to observe the lag in the development of children with DS due to the comorbidities related to the Syndrome (1-7).

The tests presented required orientation and postural balance necessary for perception (sensory information of Spatiotemporal Knowledge) and action (production of forces to manage these systems). Compensation constitutes an interaction between the musculoskeletal system and the neural and the resting state where the body is found, exerting equal and opposite strength $(28,29)$. And such interaction in people with DS is compromised by hypotonia, ligament weakness, flat foot, among other issues related to the syndrome.

Referring to the static balance tests, Beerse and $\mathrm{Wu}$ (30) point to reduced balance control in children with DS, and even considering it is satisfactory that $42.9 \%$ of the GP participants achieved the average score in the T2 and T3 tests, the percentage of children with a score of 0 in both trials was significantly high. In the CG, $100 \%$ scored 0 in T3.

A factor that can influence the results of the T2 and T3 tests represents the child's dominant side, as a generalized and consistent performance advantage in motor tasks performed with the prevailing side about performance with the nondominant side would be expected (31). However, observing the data obtained, this did not occur in the application of the tests, since only $42.9 \%$ of the $R G$ received a score of 1 with the dominant foot, and in the CG, the results were repeated in the use of both feet (Table 2).

Regarding the T4 and T5 tests, the results presented show that the dynamic balance level of the evaluated individuals is above the average compared to the results obtained in the static balance tests. With an increase in the maximum and average scores in the jump with one foot (left or right). In a study carried out with SD children, Beerse and Wu (33) stated that they typically require more time to develop motor skills and acquire more coordinated 
movement patterns. Which directly interferes with the dynamic balance that requires good motor coordination. However, a significant sample gained good results with a score of 2 $(35.7 \%$ and $28.6 \%)$ and a score of $1(28.6 \%$ and $50 \%$ ) in $\mathrm{T} 4$ and $\mathrm{T} 5$, respectively. In the $\mathrm{CG}$, in $\mathrm{T} 4$ and $\mathrm{T} 5$, the results were $100 \%$ with a score of 0 , which undermined the importance of dance practice.

The postural balance acts continuously during the changes in the situation. When the individual is static, the body control works in a certain way, and in a dynamic case, it acts in a more complex form (32). The support base remains fixed in static balance while the body mass center moves $(27,33)$. In this case, the balance must maintain the center of body mass within the support base (34). In a situation of dynamic equilibrium, both the center of mass and the support base move and the center of mass never aligns with the support base during the single support phase of the movement $(27,34)$, which develops the performance better in children with DS in dynamic equilibrium tests.

Regarding T6, where three children (21.4\%) obtained a score of 2, 50\% of the sample scored 1 , and $28.6 \%$ ( 4 children) received a score of 0 . It is significant to consider an excellent result since children with DS may be unable to jump continuously in a similar location until the age of 7. And even within the age range of this study ( 8 to 12 years old), children are unable to jump for as long as their peers who do not have the Syndrome (30). This statement is equally marked by the performance of the CG since $100 \%$ of the sample obtained a score of 0 . Considering the notes of Beerse and $\mathrm{Wu}(30)$, the percentage of $71.4 \%$ of the sample in this study who obtained a score of 1 or 2, is within a process of development of reasonable balance given the condition of children with DS.

Another crucial issue comes from the study by Jung et al. (2), for whom one of the reasons for children's difficulties in T6 is linked to the fact that the speed of muscle reaction is significantly slower in DS compared to children without the Syndrome, and there is many difficulty in vision, control motor and agility (19).

As demonstrated, these relatively significant results can, in a way, be credited to the practice of dance, as a child with DS who gains the aid of this practice, receives adequate stimuli for the development of the necessary skills to perform various physical activities, can assist in fundamental movements that promote sensory integration and postural control $(19,20)$.

Despite the significant results presented in the research, the need for further studies in this area is considered since balance is one of the critical problems in people with DS that needs to be investigated and worked on by Physical Education. It is therefore suggested to carry out new research with a broader sample, in addition to conducting pre and post-tests, and a pedagogical intervention more focused on the development of balance and other psychomotor elements and, finally, greater rigidity in determining inclusion and exclusion criteria for participation in the research.

\section{CONCLUSION}

Considering the results obtained in this study, it can be declared that children with Down Syndrome who practice dance, considering the rhythmic and coordination properties of this activity presented a satisfactory balance when compared to the Control Group that does not practice dance.

It was exposed, with this study, that there is an urgent need for the development of appropriate instruments to assess balance and other psychomotor elements for people with DS, since, with the use of batteries developed and validated for people without the Syndrome, this group will habitually be below the predicted scores due to the physical and physiological problems related to DS, and there cannot be a proper perspective on their psychomotor development. Given that they do not consider comorbidities related to the syndrome, despite the tests having been understood and performed by all study participants.

From the results obtained in this study, it is perceived that dance can represent an excellent means for the development of balance in children with DS. Especially when observed and considered the limiting factors related to comorbidities and to the syndrome. It is a possible activity in numerous environments, easy to apply and with a reasonable cost, which provides effective motor stimulation and enhances the development of people with DS.

It was concluded that the continuous and systematic practice of dance can provide a considerable development in the balance of children with DS, which can favor their insertion and permanence in physical exercise programs and sports initiation satisfactorily. 


\section{APPLICABLE REMARKS}

- Implication for health policymakers / practice / research / medical education:

1) Balance is one of the main problems in the psychomotor development of people with Down syndrome, with few studies in the literature on the subject.

2) This study evaluates the balance of children with the Syndrome who practice dance and seeks to verify its effectiveness in forming the body scheme of these children.

\section{FINANCIAL SUPPORT}

There is no financial support.

\section{DECLARATION OF INTEREST}

There is no Conflict of interest/financial disclosure.

\section{FUNDING}

Funding received from personal finance of researchers.

\section{REFRENCES}

1. Herrero D, Einspieler C, Panvequio Aizawa CY, Mutlu A, Yang H, Nogolova A, et al. The motor repertoire in 3- to 5-month old infants with Down syndrome. Res Dev Disabil. 2017;67:1-8. doi: 10.1016/j.ridd.2017.05.006 http://ncbi.nlm.nih.gov/pubmed/28586709

2. Jung HK, Chung E, Lee BH. A comparison of the balance and gait function between children with Down syndrome and typically developing children. J Phys Ther Sci. 2017;29(1):123-127. doi: 10.1589/jpts.29.123 http://ncbi.nlm.nih.gov/pubmed/28210057

3. Kim HI, Kim SW, Kim J, Jeon HR, Jung DW. Motor and Cognitive Developmental Profiles in Children With Down Syndrome. Ann Rehabil Med. 2017;41(1):97-103. doi: 10.5535/arm.2017.41.1.97 http://ncbi.nlm.nih.gov/pubmed/28289641

4. Meneghetti C, Lanfranchi S, Carretti B, Toffalini E. Visuo-spatial knowledge acquisition in individuals with Down syndrome: The role of descriptions and sketch maps. Res Dev Disabil. 2017;63:46-58. doi: 10.1016/j.ridd.2017.02.013 pmid: 28260623

5. Possebom WF, Massetti T, Silva TDd, Malheiros SRP, Menezes LDCd, Caromano FA. Desempenho em uma tarefa de labirinto no computador na síndrome de Down. Rev bras crescimento desenvolv hum. 2016:205-210.

6. Trindade AS, Nascimento MAD. Avaliação do desenvolvimento motor em crianças com síndrome de down. Revista Brasileira de Educação Especial. 2016;22(4):577-588. doi: 10.1590/s141365382216000400008

7. Ferreira-Vasques AT, Lamonica DA. Motor, linguistic, personal and social aspects of children with Down syndrome. J Appl Oral Sci. 2015;23(4):424-430. doi: 10.1590/1678-775720150102 pmid: 26398516

8. Cooley WC, Graham JM, Jr. Down syndrome--an update and review for the primary pediatrician. Clin Pediatr (Phila). 1991;30(4):233-253. doi: 10.1177/000992289103000407 pmid: 1827373

9. Alsakhawi RS, Elshafey MA. Effect of Core Stability Exercises and Treadmill Training on Balance in Children with Down Syndrome: Randomized Controlled Trial. Adv Ther. 2019;36(9):2364-2373. doi: 10.1007/s12325-019-01024-2 pmid: 31301057

10.Priosti PA, Blascovi-Assis SM, Cymrot R, Vianna DL, Caromano FA. Força de preensão e destreza manual na criança com Síndrome de Down. Fisioterapia e Pesquisa. 2013;20(3):278-285. doi: 10.1590/S1809-29502013000300013

11. Coppede AC, Campos ACd, Santos DCC, Rocha NACF. Desempenho motor fino e funcionalidade em crianças com síndrome de Down. Fisioterapia e Pesquisa. 2012;19(4):363-368. doi: 10.1590/S180929502012000400012

12.Polastri PF, Barela JA. Perception-action coupling in infants with Down syndrome: effects of experience and practice. Adapt Physic Activ Quarter. 2005;22(1):39-56. doi: 10.1123/apaq.22.1.39

13. Shiohama T, Levman J, Baumer N, Takahashi E. Structural Magnetic Resonance Imaging-Based Brain Morphology Study in Infants and Toddlers With Down Syndrome: The Effect of Comorbidities. Pediatr Neurol. 2019;100:67-73. doi: 10.1016/j.pediatrneurol.2019.03.015 pmid: 31036426

14. Malak R, Kostiukow A, Krawczyk-Wasielewska A, Mojs E, Samborski W. Delays in Motor Development in Children with Down Syndrome. Med Sci Monit. 2015;21:1904-1910. doi: 10.12659/MSM.893377 pmid: 26132100 
15. Maiano C, Hue O, Lepage G, Morin AJS, Tracey D, Moullec G. Do Exercise Interventions Improve Balance for Children and Adolescents With Down Syndrome? A Systematic Review. Phys Ther. 2019;99(5):507-518. doi: 10.1093/ptj/pzz012 pmid: 31089706

16. McGuire M, Long J, Esbensen AJ, Bailes AF. Adapted Dance Improves Motor Abilities and Participation in Children With Down Syndrome: A Pilot Study. Pediatr Phys Ther. 2019;31(1):76-82. doi: 10.1097/PEP.0000000000000559 pmid: 30557286

17.Robinson J, Siegfried I. El niño y la danza: Mirador1992.

18. de Vargas LA. A dança na educação Física. TEXTURA-Revista de Educação e Letras. 2000;2(3).

19. Gutierrez-Vilahu L, Masso-Ortigosa N, Costa-Tutusaus L, Guerra-Balic M, Rey-Abella F. Comparison of Static Balance on a Platform in Young Adults With Down Syndrome Before and After a Dance Program. Adapt Phys Activ Q. 2016;33(3):233-252. doi: 10.1123/APAQ.2015-0048 pmid: 27623608

20.Li C, Chen S, Meng How Y, Zhang AL. Benefits of physical exercise intervention on fitness of individuals with Down syndrome: a systematic review of randomized-controlled trials. Int J Rehabil Res. 2013;36(3):187-195. doi: 10.1097/MRR.0b013e3283634e9c pmid: 23778328

21.Bankoff ADP. Morfologia e cinesiologia: aplicada ao movimento humano: Guanabara Koogan2007.

22. Di Pancrazio L, Bellomo RG, Franciotti R, Iodice P, Galati V, D'Andreagiovanni A, et al. Combined rehabilitation program for postural instability in progressive supranuclear palsy. NeuroRehabilitation. 2013;32(4):855-860. doi: 10.3233/NRE-130909 pmid: 23867411

23. de Campos Oliveira G. Avaliação psicomotora à luz da psicologia e da psicopedagogia: Vozes2003.

24.Hamner T, Udhnani MD, Osipowicz KZ, Lee NR. Pediatric Brain Development in Down Syndrome: A Field in Its Infancy. J Int Neuropsychol Soc. 2018;24(9):966-976. doi: 10.1017/S1355617718000206 pmid: 29789029

25. Foley C, Killeen OG. Musculoskeletal anomalies in children with Down syndrome: an observational study. Arch Dis Child. 2019;104(5):482-487. doi: 10.1136/archdischild-2018-315751 pmid: 30472668

26. Kapandji A. Fisiologia Articular: Membro Inferior. 5a edição. Rio de Janeiro: Editora Guanabara Koogan.

27. Melo RS, Marinho S, Freire MEA, Souza RA, Damasceno HAM, Raposo MCF. Static and dynamic balance of children and adolescents with sensorineural hearing loss. Einstein (Sao Paulo). 2017;15(3):262-268. doi: 10.1590/S1679-45082017AO3976 pmid: 29091145

28. Barela JA. Estratégias de controle em movimentos complexos: ciclo percepção-ação no controle postural. Rev Paul Educ Fís. 2000;1(3):79-88.

29. Shumway-Cook A, Woollacott MH. Controle motor: teoria e aplicações práticas: Manole2003.

30. Beerse M, Wu J. Vertical stiffness and balance control of two-legged hopping in-place in children with and without Down syndrome. Gait Posture. 2018;63:39-45. doi: 10.1016/j.gaitpost.2018.04.026 pmid: 29705521

31. Teixeira LA, Paroli R. Assimetrias laterais em ações motoras: preferência versus desempenho. Motriz. 2000;6(1):1-8.

32.Rebelatto JR, de Castro AP, Sako FK, Aurichio TR. Equilíbrio estático e dinâmico em indivíduos senescentes e o índice de massa corporal. Fisioterapia em movimento. 2017;21(3).

33. Hobeika CP. Equilibrium and balance in the elderly. Ear Nose Throat J. 1999;78(8):558-566. doi: 10.1177/014556139907800810

34. Woollacott MH, Tang PF. Balance control during walking in the older adult: research and its implications. Phys Ther. 1997;77(6):646-660. doi: 10.1093/ptj/77.6.646 pmid: 9184689 